\title{
Study on the photosynthetic characteristics of Eutrema japonica (Siebold) Koidz. under the pulsed LEDs for simulated sunflecks
}

\author{
Jae Hoon Park1, Sang Bum Kim², Eung Pill Lee³, Seung Yeon Lee ${ }^{1}$, Eui Joo Kim¹', Jung Min Lee ${ }^{1}$, Jin Hee Park', \\ Kyu Tae Cho ${ }^{1}$, Heon Mo Jeong ${ }^{5}$, Seung Se Choi ${ }^{6}$, Hoey Kyung Park ${ }^{7}$ and Young Han You ${ }^{1 *}$ (D)
}

\begin{abstract}
Background: The sunfleck is an important light environmental factor for plants that live under the shade of trees. Currently, the smartfarm has a system that can artificially create these sunfleks. Therefore, it was intended to find optimal light conditions by measuring and analyzing photosynthetic responses of Eutrema japonica (Miq.) Koidz., a plant living in shade with high economic value under artificial sunflecks.

Results: For this purpose, we used LED pulsed light as the simulated sunflecks and set the light frequency levels of six chambers to $20 \mathrm{~Hz}, 60 \mathrm{~Hz}, 180 \mathrm{~Hz}, 540 \mathrm{~Hz}, 1620 \mathrm{~Hz}$, and $4860 \mathrm{~Hz}$ of a pulsed LED grow system in a plant factory and the duty ratio of the all chambers was set to 30\%, 50\%, and $70 \%$ every 2 weeks. We measured the photosynthetic rate, transpiration rate, stomatal conductance, and substomatal $\mathrm{CO}_{2}$ partial pressure of E. japonica under each light condition. We also calculated the results of measurement, $\mathrm{A} / \mathrm{Ci}$, and water use efficiency. According to our results, the photosynthetic rate was not different among different duty ratios, the transpiration rate was higher at the duty ratio of $70 \%$ than $30 \%$ and $50 \%$, and stomatal conductance was higher at 50\% and $70 \%$ than at 30\%. In addition, the substomatal $\mathrm{CO}_{2}$ partial pressure was higher at the duty ratio of 50\% than 30\% and 70\%, and A/Ci was higher at 30\% than 50\% and 70\%. Water use efficiency was higher at 30\% and 50\% than at 70\%. While the transpiration rate and stomatal conductance generally tended to become higher as the frequency level decreased, other physiological items did not change with different frequency levels.

Conclusions: Our results showed that $30 \%$ and $50 \%$ duty ratios could be better in the cultivation of E. japonica due to suffering from water stress as well as light stress in environments with the $70 \%$ duty ratio by decreasing water use efficiency. These results suggest that E. japonica is adapted under the light environment with nature sunflecks around 30-50\% duty ratio and low light frequency around $20 \mathrm{~Hz}$.
\end{abstract}

Keywords: Duty ratio, Eutrema japonica, Light frequency, LED pulsed light, Plant factory, Sunfleck

\section{Background}

Due to the difficulty in securing stable food resources as a result of climate change occurring internationally, plant factories that can consistently grow food regardless of the weather have attracted attention (Um et al. 2010). A plant factory is a production facility that has the advantage of continuously producing high-quality plants

\footnotetext{
* Correspondence: youeco21@kongju.ac.kr

'Department of Biological Science, Kongju National University, Gongju 32588, Republic of Korea

Full list of author information is available at the end of the article
}

through artificial control of cultivation conditions such as light, temperature, humidity, and carbon dioxide concentration (Luna-Maldonado et al. 2016), and can produce larger quantities of plants compared to general outdoor culture because it can cultivate plants no matter the weather (Luna-Maldonado et al. 2016). For this reason, red and blue lights are commonly used in plant cultivation studies in plant factories (Kim and You 2013, Kim et al. 2013; Im et al. 2013; Kim et al. 2014; Park et al., 2016; Phansurin et al. 2017; Oh et al. 2019).

(c) The Author(s). 2021 Open Access This article is licensed under a Creative Commons Attribution 4.0 International License, which permits use, sharing, adaptation, distribution and reproduction in any medium or format, as long as you give appropriate credit to the original author(s) and the source, provide a link to the Creative Commons licence, and indicate if changes were made. The images or other third party material in this article are included in the article's Creative Commons licence, unless indicated otherwise in a credit line to the material. If material is not included in the article's Creative Commons licence and your intended use is not permitted by statutory regulation or exceeds the permitted use, you will need to obtain permission directly from the copyright holder. To view a copy of this licence, visit http://creativecommons.org/licenses/by/4.0/ 
Because of these advantages, studies on system automation, light wavelengths for optimal plant growth conditions, and breeding of varieties are being carried out in South Korea at national and private research institutes using plant factories. Among private enterprises, developers of programs for product sales or environment control operate plant factories (Kim et al. 2011). In the case of Japan, plant factories that can produce large quantities of plants regardless of weather or place have attracted attention because Japan's food self-sufficiency rate was about $41 \%$ and grain self-sufficiency rate was about $28 \%$ as of 2008 , which were the lowest among OECD countries. This presents serious problems in securing food resources, but large-scale farming is difficult in Japan due to the characteristics of Japanese smallscale agriculture because of the considerable amount of deserted land (Takatsuji 2010).

Plant factories are largely divided into types that use sunlight and fully controlled types, and the former are known to be affected by weather and are needed very much when producing fruits and vegetables (Takatsuji 2010). The fully controlled types only use artificial light to produce plants, and they are optimal for cultivation studies using LED light (Watanabe 1997).

Since LEDs only emit light in a short wavelength region, they can be combined into variable wavelength regions and can be installed very closely to plants being cultivated because they do not produce much heat since they hardly emit heat energy in the infrared region (Watanabe 1997), which is useful for plant cultivation. Also, LEDs are able to blink on and off quickly (Ansaari and Weerakoon 2014). Thanks to these advantages, when LEDs are used, the wavelengths of lights, lightdark cycles, amount of light, etc. can be precisely controlled to fit the physiological characteristics of certain plants (Watanabe 1997). In particular, since LEDs enable the control of light-dark cycles, studies on plant photosynthetic responses using the advantages of LEDs have been continuously conducted in South Korea and abroad (Ikeda et al. 1985; Mori et al. 2002a; Mori et al. 2002b; Son et al. 2016).

The lights that are mainly used in plant factories are the red and blue lights used for photosynthesis by plants, which are generally known to be absorbed by the photosynthesis pigments chlorophyll $\mathrm{a}$ and $\mathrm{b}$ (Hopkins and Huner 2008). For this reason, red and blue lights are commonly used in plant cultivation studies in plant factories (Kim et al. 2013; Im et al. 2013; Phansurin et al. 2017; Oh et al. 2019). In addition, some studies delivered signals directly to photoreceptors such as cryptochrome, phototropin, and phytochrome to affect plant physiology and development (Hopkins and Huner 2008).

Furthermore, a light condition used together with light quality is the control of the light-dark cycle, which is to regulate the duty ratio and the frequency being supplied. The duty ratio is the percent of light time per unit cycle and frequency is the number of cycles of light/dark time per unit time of light/dark pulsed light (Mori et al. 2002a). The control of duty ratios and frequency periodically controls the light supply so that photosynthesis may be generated more efficiently than by continuously supplying light, because it has been reported that the reaction rate of chlorophyll P680 centered on photosystem II is about $200 \mu \mathrm{s}$ and that of chlorophyll P700 centered on photosystem I is about $20 \mathrm{~ms}$ (Mori et al. 2002a). In addition, the control of the duty ratio is considered to reduce power consumption more efficiently by reducing the amount of light, which uses the most electricity in plant factories.

Although some studies on the growth and development responses of lettuce using duty ratios and frequency (or pulsed period) in plant factories have been reported in South Korea and Japan (Mori et al. 2002a; Mori et al. 2002b; Son et al. 2018), studies on a high value-added crop such as E. japonica using light-dark cycles have rarely been conducted. Therefore, this study was intended to observe the changes of photosynthetic traits under pulsed light conditions by controlling duty ratio and light frequency on E. japonica using mixed red and blue light known to be mainly needed for plant photosynthesis within the plant factory.

\section{Materials and methods Study target plant}

Eutrema japonica, the plant used in this study, is a perennial rhizocarpous herbaceous plant that belongs to the family Brassicaceae (Zhou et al. 2001). The species is native to Japan and has been cultivated and also naturalized in China, Russia (Far East), Korea, and Taiwan which habitats are usually wet areas along streams in mountains (Zhou et al. 2001; Lee 2014; Oh 2007a, b).

E. japonica is a valuable crop as a condiment herb and recently often used in Western cuisine as well as in Japan (Sultana and Savage 2008). For this reason, this crop is also cultivated in New Zealand (Sultana and Savage 2008). The main habitat of E. japonica is known for the valleys around water streams (Lee 2010). Since the range of optimal growth environments of E. japonica is narrow compared to other crops, cultivation in an outdoor environment is relatively difficult (Rural Development Administration 2015). Therefore, cultivation studies in a fully controlled plant factory that is not affected by environmental changes and enables the control of physical environments are judged effective for the commercial use of E. japonica.

In South Korea, E. japonica grows wild on the northwest slope in the Acer okamotoanum-Fagus engleriana community in Seo-myeon, Ulleungdo Island, and the 
valley region of the north slope in the Alnus maximowiczii-F. engleriana community in Nari Basin. Since the tree layer coverage of the region where E. japonica communities were dominant is $70-80 \%$ (Kim et al. 2008), E. japonica is able to establish and grow under shaded environment with this range of coverage in the wild area. Therefore, studying the photosynthetic responses of $E$. japonica according to sunflecks is judged to enable more efficient cultivation in plant factories. Therefore, the cultivation in plant factories of E. japonica using pulsed lights is judged to fit for studying the photosynthetic responses of E. japonica, according to sunflecks.

To that end, seedlings of E. japonica were bought from the Specialized Crop Research Institute of Gangwon-do Agricultural Research and Extension Services in Korea, and seedlings of similar sizes were selected with eyes in March. These were transplanted into round pots (D 12 $\mathrm{cm} \times \mathrm{H} 15 \mathrm{~cm}$ ) with one per pot.

\section{Cultivation and management}

E. japonica was cultivated in a $360(\mathrm{~W}) \times 60(\mathrm{~L}) \times 230$ (H) plant factory (LED grow light system, Parus Co.) in Gongju National University for a total of 3 months from March to May. The plant factory included 6 chambers installed with plants in a $120(\mathrm{~W}) \times 52(\mathrm{~L})$ cultivation bed. The walls of each cultivation bed were colored white to enhance light reflectivity (Mori et al. 2002a). The temperature and humidity of the plant factory were maintained at $22 \pm 4.00^{\circ} \mathrm{C}$ and $67 \pm 8.05 \%$ on average, respectively, using an air cooler, a fan heater, and a humidifier. The environmental data were transmitted to a computer every $10 \mathrm{~min}$ for $24 \mathrm{~h}$ via an LCSEMS sensor. The $\mathrm{CO}_{2}$ concentration was $501.41 \pm 40.35 \mathrm{vpm}$ measured by a photosynthesis measuring apparatus (LCi Ultra Compact Photosynthesis System, ADC) when measuring photosynthesis.

The soil used was a mixture of sand with the same particle size and bed soil (Hanareun bed soil for horticulture, Shinseong Mineral) at a ratio of 4:1. Three plants were placed for each light condition and grown for 3 months under a total of 18 light conditions (Table 1). The supplied amounts of water were $400 \mathrm{ml}$, the maximum water capacity, at intervals of 1 to 2 days. The fertilizer consisting of $70 \%$ organic matter, $4.3 \%$ nitrogen, $1.7 \%$ phosphoric acid, and $1 \%$ potassium (Heuksal Gold, KG Chemical Co., Ltd) was diluted to $3 \%$ with water and supplied once a week.

\section{Light treatment}

To find the optimal light conditions for the physiological characteristics of E. japonica, the $\mathrm{R}+\mathrm{B}$ mixed light ( $\mathrm{R}$ to $B$ ratio $=1: 1)$ of LEDs that is commonly used in plant factories was used in this study. Since the reaction rates of chlorophyll P680 (photosystem II) and P700
Table 1 The light quality, duty ratio, and frequency of the 18 experimental conditions

\begin{tabular}{lll}
\hline Light quality & Duty ratio (\%) & Frequency $\mathbf{( H z )}$ \\
\hline Red + Blue & 20 \\
& 60 \\
& 180 \\
& 540 \\
& 1620 \\
& 4860 \\
& 20 \\
& 60 \\
& 60 \\
& 180 \\
& 540 \\
& 1620 \\
& 4860 \\
& 20 \\
& 60 \\
& 180 \\
& 540 \\
& 1620 \\
& 4860 \\
&
\end{tabular}

(photosystem I) are known to be $200 \mu \mathrm{s}(50 \mathrm{~Hz}$ by calculation) and $20 \mathrm{~ms}(5000 \mathrm{~Hz}$ by calculation), respectively (Mori et al. 2002a), the light frequency levels of individual chambers located in the plant factory were set to 20 $\mathrm{Hz}, 60 \mathrm{~Hz}, 180 \mathrm{~Hz}, 540 \mathrm{~Hz}, 1620 \mathrm{~Hz}$, and $4860 \mathrm{~Hz}$, considering the foregoing. The duty ratio was first set to $50 \%$ and it was changed to $30 \%$ and $70 \%$ every 2 weeks. The leaf-related physiological characteristics were measured at the end of every interval, because plant physiological acclimation is known to be able to occur rapidly within several days when the light environment changes (Hogewoning et al. 2006; Athanasiou et al. 2010).

In a study conducted by Mori et al. (2002b), when the amount of light was set in the plant factory, the light-dark cycle for each chamber was set and then the amount of light was set as constant. In this study, however, all the chambers were set to have continuous light to uniformly set the amount of light, and the light-dark cycle was set differently. The method of Mori et al. (2002b) has the advantage of being able to maintain a constant photon flux density per unit time but has the disadvantage that the light intensity varies depending on the duty ratio during the light irradiation period. Plants may have different physiological responses depending on light intensity (Lambers et al. 2008). In terms of ecology, since the species that constitute understory vegetation have adapted to certain sunflecks coming through the crown layer of the forest in each habitat (Chazdon 
and Pearcy 1991), it was judged that to clearly understand the species-specific photosynthetic responses to light-dark cycles, the light intensity should be constant during the period of light irradiation.

All the chambers were set to have continuous light to have the same amount of light (average photosynthetic

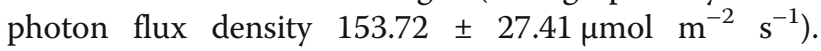
Thereafter, the light-dark cycle was set differently. Therefore, the amount of light was maintained the same based on when the duty ratio and frequency were not controlled. This means the amount of light during the time when light that was irradiated was the same among all chambers.

\section{Analysis of physiological characteristics}

To analyze the physiological characteristics of E. japonica, photosynthesis was measured on the last day of each week set to different duty ratio. At that time, the photosynthetic rate $\left(A ; \mu \mathrm{mol} \mathrm{m}{ }^{-2} \mathrm{~s}^{-1}\right)$, the transpiration rate $\left(E ; \mathrm{mmol} \mathrm{m}^{-}\right.$ ${ }^{2} \mathrm{~s}^{-1}$ ), stomatal conductance (gs; $\mathrm{mmol} \mathrm{m}^{-2} \mathrm{~s}^{-1}$ ), and substomatal $\mathrm{CO}_{2}$ partial pressure $(\mathrm{Ci}$; vpm) were measured 54 replications per duty ratio ( 3 replications $\times 18$ plant) and 27 replications ( 3 replications $\times 9$ plant) per light frequency condition using a photosynthesis measuring apparatus (LCi Ultra Compact Photosynthesis System, ADC). $A / \mathrm{Ci}$ and water use efficiency $\left(\mu \mathrm{mol} \mathrm{CO}_{2} / \mathrm{mmol}\right.$ $\mathrm{H}_{2} \mathrm{O}$ ) were calculated using the results of measurement.

\section{Statistical analysis}

To analyze the effects of duty ratios and frequency on the photosynthetic activity of E. japonica, Kruskal-Wallis tests were carried out among 30\%, 50\%, and 70\% duty ratio within each light frequency and among $20 \mathrm{~Hz}, 60$ $\mathrm{Hz}, 180 \mathrm{~Hz}, 540 \mathrm{~Hz}, 1620 \mathrm{~Hz}$, and $4860 \mathrm{~Hz}$ of light frequency within each duty ratio using Statistica 8 (Statsoft Inc.) and a post hoc test followed the method of Siegel and Castellan Jr. (1988).

\section{Results}

\section{Duty ratio}

While the $A$ did not change with different duty ratios, the $E$ was shown to be the highest at the duty ratio of $70 \%$ (Fig. 1). The gs was higher at the duty ratios of $50 \%$ and $70 \%$ than at $30 \%$ and the $\mathrm{Ci}$ was highest at $50 \%$ (Fig. 1). The $\mathrm{A} / \mathrm{Ci}$ was highest at $30 \%$ and the WUE was higher at $30 \%$ and $50 \%$ than at 70\% (Fig. 1).

\section{Light frequency}

The $E$ was highest at $20 \mathrm{~Hz}$ and lowest at $1620 \mathrm{~Hz}$ (Fig. 2). The gs was highest at $20 \mathrm{~Hz}$ and lowest at $1620 \mathrm{~Hz}$ and $4860 \mathrm{~Hz}$ (Fig. 2). However, the $A, \mathrm{Ci}, A$ / $\mathrm{Ci}$, and WUE showed no statistically significant differences with different levels of light frequency (Fig. 2).
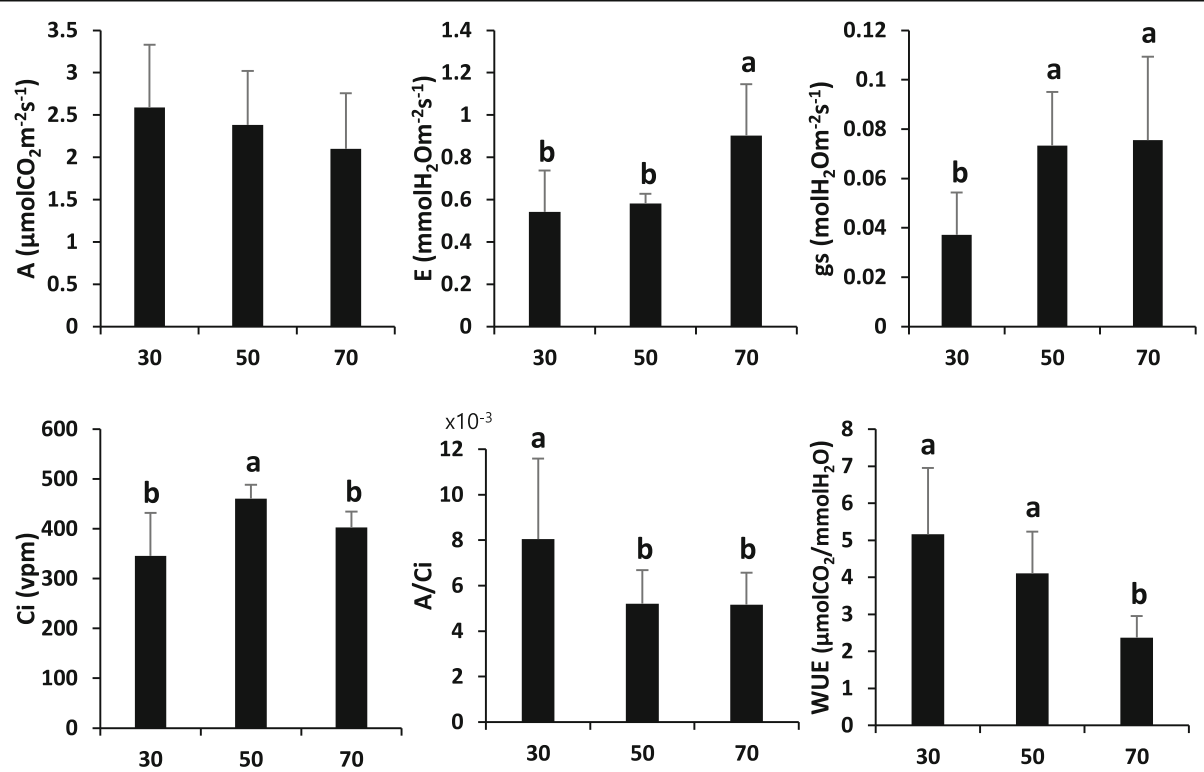

Fig. 1 The averages of photosynthetic rate $\left(A ; \mu \mathrm{mol} \mathrm{m} \mathrm{m}^{-2} \mathrm{~s}^{-1}\right)$, transpiration rate $\left(E ; \mathrm{mmol} \mathrm{m}^{-2} \mathrm{~s}^{-1}\right)$, stomatal conductance $\left(\mathrm{gs} ; \mathrm{mol} \mathrm{m}^{-2} \mathrm{~s}^{-1}\right)$, substomatal $\mathrm{CO}_{2}$ partial pressure ( $\mathrm{Ci}$; vpm), photosynthetic rate (A/Ci) per substomatal $\mathrm{CO}_{2}$ partial pressure, and water use efficiency (WUE; $\mu$ mol $\mathrm{CO}_{2} / \mathrm{mmol} \mathrm{H}_{2} \mathrm{O}$ ) on 54 replications per duty ratio condition within $20 \mathrm{~Hz}, 60 \mathrm{~Hz}, 180 \mathrm{~Hz}, 540 \mathrm{~Hz}, 1620 \mathrm{~Hz}$, and $4860 \mathrm{~Hz}$ of light frequency. The error bars and letters on the bars refer to the sample standard deviations and significant differences among the duty ratio groups, respectively. A graph without the letters on the bars means that there are no significant differences among the duty ratio groups 

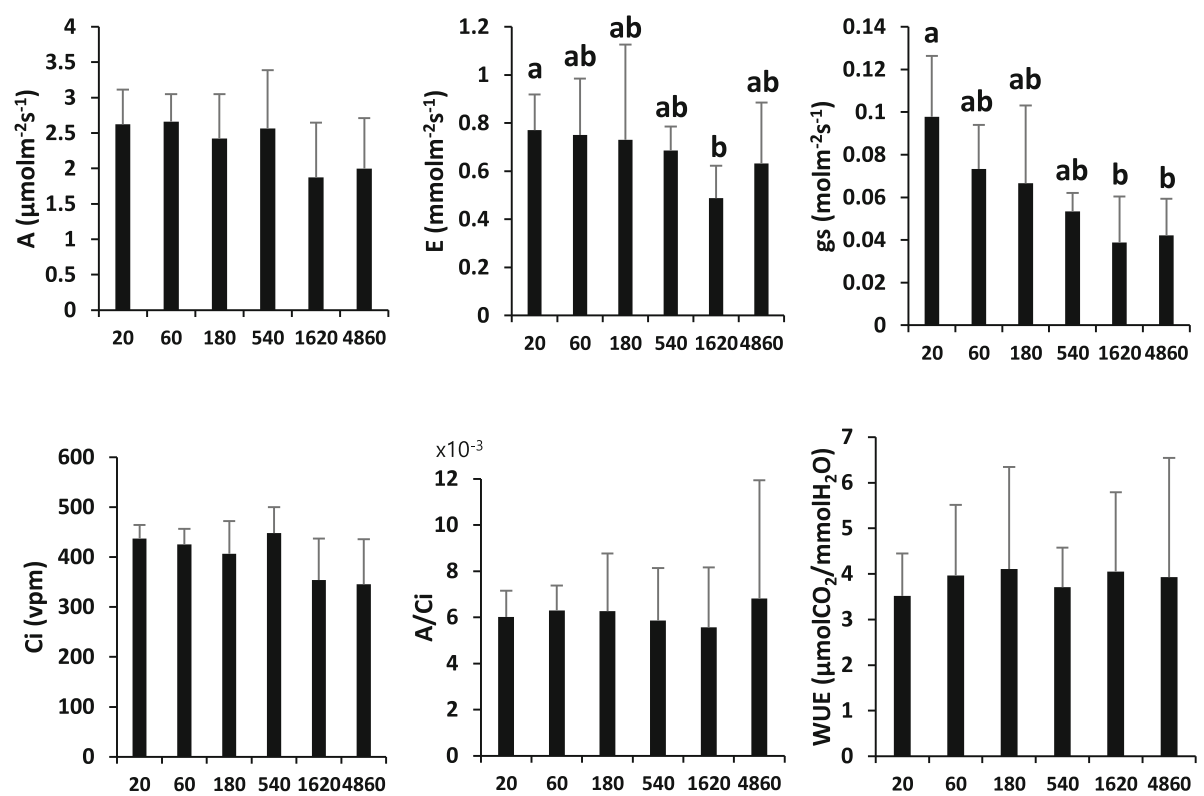

Fig. 2 The averages of photosynthetic rate $\left(A ; \mu \mathrm{mol} \mathrm{m} \mathrm{s}^{-1}\right)$, transpiration rate $\left(E_{;}\right.$mmol m $\left.\mathrm{m}^{-2} \mathrm{~s}^{-1}\right)$, stomatal conductance $\left(\mathrm{gs} ; \mathrm{mmol} \mathrm{m} \mathrm{m}^{-2} \mathrm{~s}^{-1}\right)$, substomatal $\mathrm{CO}_{2}$ partial pressure ( $\left.\mathrm{Ci} ; \mathrm{vpm}\right)$, photosynthetic rate $(\mathrm{A} / \mathrm{Ci})$ per substomatal $\mathrm{CO}_{2}$ partial pressure, and water use efficiency (WUE; $\mu$ mol $\mathrm{CO}_{2} / \mathrm{mmol} \mathrm{H}_{2} \mathrm{O}$ ) on 27 replications of E. japonica per light frequency within $30 \%, 50 \%$, and $70 \%$ of duty ratio. The error bars and letters on the bars refer to the sample standard deviations and significant differences among the frequency groups, respectively. The graphs without the letters on the bars mean that there are no significant differences among the frequency groups

\section{Discussion}

\section{Photosynthetic rate on duty ratios}

The A of E. japonica was not different among different duty ratios (Fig. 1). But in other experiments, changes in As according to different duty ratios were observed in the case of Lactuca sativa L. cv. "Natsuyo-Saradana"; Lactuca sativa L. cv. "Sunmang", a vegetable; and Silene capitata Kom., a native plant (Mori et al. 2002a; Mori et al. 2002b; Son et al. 2016; Park et al. 2018). However, in this study, although the $A$ of E. japonica had no difference statistically, it is not thought to mean that the $A$ is not affected by the light cycle control because the $E$ of $E$. japonica changed when the duty ratio was controlled.

\section{Transpiration rate on duty ratios}

The $E$ of E. japonica was higher at the duty ratio of $70 \%$ than at $30 \%$ or $50 \%$ (Fig. 1). Transpiration plays a role in forming the tension to pull water up from the roots but is greatly affected by photosynthetic activity (Lambers et al. 2008), and water vapor is mainly released due to the difference in water vapor pressure between the inner space of the leaves and the outside in the process of opening of the stomata to absorb $\mathrm{CO}_{2}$ (Slatyer 1971). Therefore, the reason why the $A$ was shown to be the same when the duty ratio was set differently is that $E$. japonica was trying to maintain a stable $A$ by becoming physiologically acclimated to different light environments. Since $90-95 \%$ of transpiration is carried out by stomata (Hopkins and Huner 2008), changes in the $E$ shown are judged to result from changes in the activity of the stomatal opening and closing due to the light environment.

\section{Stomatal conductance on duty ratios}

The gs was higher at the duty ratios of $50 \%$ and $70 \%$ than at $30 \%$ (Fig. 1). Since most of the transpiration in a plant occurs through the stomata, compared to the results of $E$, it could be seen that both the $E$ and gs of $E$. japonica were relatively low in environments where the duty ratio was $30 \%$ and high in environments where the duty ratio was $70 \%$ (Fig. 1). Therefore, it seems likely that relatively more stomata are closed in environments where the duty ratio is 30\% compared to environments where the duty ratio is $70 \%$. However, on reviewing the results of $E$ and gs in an environment where the duty ratio was $50 \%$, it could be seen that the $E$ was relatively low, but gs was high (Fig. 1). This difference is thought to be related to the results of the $\mathrm{Ci}$.

\section{Substomatal $\mathrm{CO}_{2}$ partial pressure on duty ratios}

When comparing the $50 \%$ duty ratio to the $30 \%$ ratio, the higher gs means that the stomata is more open, although the Es were no different (Fig. 1). But the higher $\mathrm{Ci}$ means that the more photorespiration occurs (Fig. 1). Moreover, $A / \mathrm{Ci}$ was lower, which means that $\mathrm{CO}_{2}$ accumulated inside the leaves does not flow well into the chloroplasts, where photosynthesis occurs (Lambers et al. 2008). Although not measured in this study, this is 
thought to be due to heat radiation that occurs in the process of converting excessive light energy into heat energy (Hopkins and Huner 2008; Porcar-Castell et al. 2006). These results are judged to be caused by photoinhibition by light stress in environments with a $50 \%$ duty ratio compared to $30 \%$.

Comparing the $70 \%$ duty ratio to the $50 \%$ ratio, although there was no difference in gs, the higher $E$ indicates that an increase in $E$ is due to a factor different from the opening and closing controls of stomata. It is thought that this has to do with the increase in leaf temperature and osmotic pressure. Because the water vapor pressure inside leaves is affected by leaf temperature (Renou et al. 1990), further increases in leaf temperature may cause an increasing $E$ in the $70 \%$ duty ratio rather than the $50 \%$ duty ratio. Also, since water potentials in plants are generally affected by hydrostatic and osmotic potentials (Lambers et al. 2008), it is thought to use osmotic pressure to increase $E$ in the $70 \%$ duty ratio. For these reasons, the decline of $\mathrm{Ci}$ seems to be due to the simultaneous increase in the water vapor pressure inside the leaves by increasing $E$ and reducing the partial pressure of $\mathrm{CO}_{2}$. Through this process, $A / C i$ is judged to be similar to when the duty ratio is $50 \%$, resulting in a constant photosynthesis rate.

\section{Water use efficiency on duty ratios}

WUE was higher when the duty ratio was $30 \%$ and 50\% than when it was $70 \%$ (Fig. 1). When comparing the $50 \%$ duty ratio to the $30 \%$ ratio, there was no difference in WUE because of no changes in $\mathrm{A}$ and $\mathrm{E}$ by duty ratio (Fig. 1). In this environment, considering the stomata was open more because of light stress than the 30\% duty ratio, although thermal accumulation occurs within the plant, it appears that $E$ remains constant because it is inhibited by the internal $\mathrm{CO}_{2}$ partial pressure in the leaves produced by photorespiration. It also seems that the $A$ remains constant due to the increasing $\mathrm{Ci}$, although $\mathrm{CO}_{2}$ inflow into the chloroplast is not well achieved.

Comparing the $70 \%$ duty ratio to the $50 \%$ ratio, WUE decreased further due to an increase in $E$. Therefore, it is judged that a larger amount of water is needed to maintain a constant $A$. In addition, the increase in $E$ at the $70 \%$ duty ratio is thought to be caused by osmotic pressure, so some of the energy acquired through photosynthesis could be used to increase E.

\section{Responses on light frequency}

As for the frequency, since the $E$ and gs broadly tend to be higher when the frequency is lower (Fig. 2), it seems likely that the lower the frequency is, the more stomata are closed. However, although the results of measurement of the $\mathrm{E}$ and gs were shown to be statistically significant, it seemed that there was no evidence of a significant effect on the activity of photosynthesis of $E$. japonica. In general, it has been reported that when sunflecks occur temporarily in the natural environment, the stomata of plants open rapidly and then close slowly in the dark period (Porcar-Castell and Palmroth 2012).

Given the foregoing, it is judged that E. japonica closed more stomata in environments where the frequency was lower and thus the shade time was relatively longer but did not close many stomata in environments where the frequency was higher and thus the dark period was relatively shorter. This result may be related to dynamic energy flow under pulsed light on the photosynthesis. According to Porcar-Castell et al. (2006), under a very small time scale $(<1 \mathrm{~s})$, electron transport rate does not rapidly decrease in shade time by nonphotochemical quenching (NPQ). Therefore, in this study, stomatal closing may be able to be active under high frequency for difficult relaxation by NPQ (PorcarCastell et al. 2006). However, since it is possible that the effect of frequency did not appear well in environments with a small amount of light (Mori et al. 2002a), the effects of frequency on the development, growth, and physiology of $E$. japonica should be checked with larger amounts of light. For knowing these reason, further physiological research is needed.

\section{Conclusions}

Individuals of E. japonica are known to grow under trees in valleys with deciduous trees well-shaded in natural environments (Kim et al. 2008). These are often observed in the mountain streams with gravels and are cultivated in the soils and streams under shaded conditions such as bases of some trees or houses in Japan (Sultana and Savage 2008). Therefore, it is thought that they have adapted at some light conditions with certain periodic or aperiodic sunflecks.

In relation to sunflecks, the $A$ s saturated and shaded on the daylight by sunflecks are around $4-8 \mu \mathrm{mol} \mathrm{m} \mathrm{m}^{-2}$ $\mathrm{s}^{-1}$ and $0.5-2 \mu \mathrm{mol} \mathrm{m} \mathrm{m}^{-2} \mathrm{~s}^{-1}$, respectively, of the sapling of Acer rubrum, Cornus florida, Liquidambar styraciflua, and Liriodendron tulipifera and the temperate trees under Pinus taeda plantation (Numburg and Ellsworth 2000). Concerning a herbaceous plant, the trend reported sunflecks caused their higher photosynthetic rate (Eliás 2014). However, these reports seem to be contrary with our result that the $A$ is constant around $2-3 \mu \mathrm{mol}$ $\mathrm{m}^{-2} \mathrm{~s}^{-1}$ on the changing duty ratio. But the trends of $E$ and gs are higher than shade time similar to our results.

The reason for this difference is not clear. But, first, it may be based on different shade time and physical environment because these studies generally were researched with variable shade time in nature conditions unlike artificial pulsed light with very short shade time $(<1 \mathrm{~s})$ and 
monotonous physical environment in this study. Second, it may be based on the amount of light. The PPFD ave is defined to $P P F D_{l p} \times$ duty ratio and if $\mathrm{PPFD}_{\mathrm{lp}}$ is different, the $A$ is also able to change at the same duty ratio and frequency (Jishi et al. 2018), but the $\mathrm{PPFD}_{\mathrm{lp}}$ is same among light conditions in this study. Third, it may be based on species-specific adaption of them. But the further study is needed for more deep understanding these. In summary, it can be seen that E. japonica undergoes low environmental stress under low light and consequently showed higher WUE in environments where the duty ratio was $30 \%$ and $50 \%$ than $70 \%$. It can be seen that E. japonica has less environmental stress under low light, as a result of which E. japonica shows higher WUE in an environment with a duty ratio of $30 \%, 50 \%$ than $70 \%$.

\section{Abbreviations}

A: Photosynthetic rate; E: Transpiration rate; gs: Stomatal conductance; Ci: Substomatal $\mathrm{CO}_{2}$ partial pressure; WUE: Water use efficiency; PPFD ave: Average photosynthetic photon flux density; PPFD 1 : Light-period photosynthetic photon flux density

\section{Acknowledgements}

This work was supported by a research grant from Kongju National University in 2017 (project no. 2017-0170-01)

\section{Authors' contributions}

Jae Hoon Park designed and performed the experiments, collected and analyzed data, and wrote the manuscript. Sang Bum Kim performed the experiments, collected and analyzed data. Eung Pill Lee, Seung Yeon Lee, Eui Joo Kim, Jung Min Lee performed the experiments and collected data. Jin Hee Park, Kyu Tae Cho, Heon Mo Jeong, Seung Se Choi, and Hoey Kyung Park reviewed the manuscript. Young Han You designed the experiments, analyzed data, and reviewed the manuscript. The authors read and approved the final manuscript.

\section{Funding}

This work was supported by a research grant from Kongju National University in 2017 (project no. 2017-0170-01)

\section{Availability of data and materials}

Not applicable.

\section{Ethics approval and consent to participate}

Not applicable.

\section{Consent for publication}

Not applicable.

\section{Competing interests}

The authors declare no competing interests.

\section{Author details}

${ }^{1}$ Department of Biological Science, Kongju National University, Gongju 32588, Republic of Korea. ${ }^{2}$ Soldan Inc., Seoul 05854, Korea. ${ }^{3}$ Invasive Alien Species Research Team, National Institute of Ecology, Seocheon 33657, Republic of Korea. ${ }^{4}$ Plant Research Team, Nakdonggang National Institute of Biological Resources, Sangju 37242, Republic of Korea. ${ }^{5}$ Team of Climate Change Research, National Institute of Ecology, Seocheon 33657, Republic of Korea. ${ }^{6}$ Team of National Ecosystem Survey, National Institute of Ecology, Seocheon 33657, Republic of Korea. ${ }^{7}$ UniconKorea, Techno 8-ro, Yuseong-gu, Daejon, Republic of Korea.
Received: 27 December 2020 Accepted: 27 January 2021

Published online: 18 February 2021

\section{References}

Ansaari A, Weerakoon D. Control of light intensity of LEDs for outdoor lighting. International Journal of Science, Engineering and Technology Research. 2014; 3(12):3244-8

Athanasiou K, Dyson BC, Webster RE, Johnson GN. Dynamic acclimation of photosynthesis increases plant fitness in changing environments. Plant physiol. 2010;152:366-73.

Chazdon RL, Pearcy RW. The importance of sunflecks for forest understory plants. Bioscience. 1991;41(11):760.

Eliáš P. Sunflecks in forest communities and their importance for plant life in a forest understorey. Mendel Bioclimatology. 2014;Sep(3-5):62-70.

Hogewoning SW, Trouwborst G, Engbers GJ, Harbinson J, van leperen W, Ruijsch J, Schapendonk AHCM, Pot CS, van Kooten O. Plant physiological acclimation to irradiation by light-emitting diodes (LEDs). ISHS Acta Horticulturae. 2006: 761:183-91.

Hopkins WG, Huner NPA. Introduction to plant physiology. 4th ed. Hoboken: Wiley; 2008.

Ikeda A, Nakayama S, Yamasaki H, Anzai YA. Power source for pulsed light illumination and its application to plant culture. T. SICE. 1985;21(7):765-7.

Im JU, Yoon YC, Seo KW, Kim KH, Moon AK, Kim HT. Effect of LED light wavelength on Chrysanthemum growth. Protected Hort Plant Fac. 2013;22(1): 49-54

Jishi T, Matsuda R, Fujiwara K. Effects of photosynthetic photon flux density, frequency, duty ratio, and their interactions on net photosynthetic rate of cos lettuce leaves under pulsed light: explanation based on photosynthetic-intermediate pool dynamics. Photosynthesis Research. 2018;136:371-8

Kim DE, Lee HJ, Kang DH, Lee Gl, Kim YH. Effects of artificial light sources on the photosynthesis, growth and phytochemical contents of butterhead lettuce (Lactuca sativa L.) in the plant factory. Protected Hort. Plant Fac. 2013;22(4): 392-9.

Kim HR, You YH. Effects of red, blue, white, and far-red LED source on growth responses of Wasabia japonica seedlings in plant factory. Kor J Hort Sci Technol. 2013;31(4):415-22.

Kim MY, So SK, Han KS, Lee JH, Park GS, Song HK. Vegetation and soil properties of Wasabia japonica population. Kor J Env Eco. 2008;22(5):530-5.

Kim SB, Lee KM, Kim HR, You YH. Effects of light sources, light quality on the growth response of leafy vegetables in closed-type plant factory system. KJEE. 2014;47(1):32-40.

Kim YH, Kim DE, Lee Gl, Kang DH, Lee HJ. Current status and development direction of the domestic and overseas for the artificial plant factory. Kor J Hort Sci Technol. 2011;29(special issue 2):37.

Lambers H, Chapin FS III, Pons TL. Plant physiological ecology 2nd edn. New York: Springer; 2008.

Lee TB. Coloured flora of Korea (I). 2nd ed. Seoul: Hyangmoonsa publishing Co.; 2014.

Lee YN. New flora of Korea (I). 3nd ed. Seoul: Kyo-Hak publishing Co.; 2010.

Luna-Maldonado Al, Vidales-Contreras JA, Rodriquez-Fuentes $\mathrm{H}$. Editorial: Advances and trends in development of plant factories. Front Plant Sci. 2016; 7:1848.

Mori Y, Takatsuji M, Yasuoka T. Effects of pulsed-red LD light on the growth of a plant. Rev Laser Eng. 2002a;30(10):602-5.

Mori Y, Takatsuji M, Yasuoka T. Effects of pulsed white LED light on the growth of lettuce. J Soc High Technol Agric. 2002b;14(3):136-40.

Numburg E, Ellsworth DS. Photosynthetic sunfleck utilization potential of understory saplings growing under elevated $\mathrm{CO}_{2}$ in FACE. Oecologia. 2000; 122:163-74.

Oh BU. BRASSICACEAE Burnett (CRUCIFERAE Juss., nom. alt.). In: The genera of vascular plants of Korea (Flora of Korea Editorial Committee ed.). Seoul. (in English): Academy Publishing Co; 2007a.

Oh BU. BRASSICACEAE Burnett (CRUCIFERAE Juss., nom. alt.). In: The genera of vascular plants of Korea (Flora of Korea Editorial Committee ed.). Seoul. (in Korean): Academy Publishing Co; 2007b.

Oh SI, Lee JH, Lee AK. Growth, antioxidant concentrations and activity in sedum takesimense as affected by supplemental LED irradiation with light quality. Hortic Sci Technol. 2019;37(5):589-97. 
Park JH, Lee EP, Han YS, Lee SI, Cho KT, Hong YS, You YH. The effects of LEDs and duty ratio on the growth and physiological responses of Silene capitata Kom., endangered plant, in a plant factory. J Eco Env. 2018;42:21.

Park JH, Lee EP, Lee SI, Jang RH, An KH, You YH. Effects of the light source of LEDs on the physiological and flowering response of endangered plant Silene capitate Kom. Korean J Environ Ecol. 2016;30(5):821-8.

Phansurin W, Jamaree T, Sakhonwasee S. Comparison of growth, development, and photosynthesis of Petunia grown under white or red-blue LED lights. Hortic Sci Technol. 2017;35(6):689-99.

Porcar-Castell A, Back J, Juurola E, Hari P. Dynamics of the energy flow through photosystem II under changing light conditions: a model approach. Funct Plant Biol. 2006;33:229-39.

Porcar-Castell A, Palmroth S. Modelling photosynthesis in highly dynamic environments: the case of sunflecks. Tree Physiology. 2012;32:1062-5.

Renou JL, Gerbaud A, Just D, Andre M. Differing substomatal and chloroplastic $\mathrm{CO}_{2}$ concentrations in water-stressed wheat. Planta. 1990;182:415.

Rural Development Administration. 2015. https://www.nongsaro.go.kr. Accessed 30 Jan 2020

Siegel S, Castellan NJ Jr. Nonparametric statistics for the behavioral sciences (2nd ed.). New York: Mcgraw-Hill Book Company; 1988.

Slatyer RO. Effect of errors in measuring leaf temperature and ambient gas concentration on calculated resistances to $\mathrm{CO}_{2}$ and water vapor exchanges in plant leaves. Plant Physiol. 1971;47:269-74.

Son KH, Jeon YM, Oh MM. Application of supplementary white and pulsed lightemitting diodes to lettuce grown in a plant factory with artificial lighting. Hortic. Environ. Biotechnol. 2016;57(6):560-72.

Son KH, Lee SR, Oh MM. Comparison of lettuce growth under continuous and pulsed irradiation using light-emitting diodes. Hortic Sci Technol. 2018;36(4): $542-51$.

Sultana T, Savage GP. Wasabi-Japanese Horseradish. Bangladesh J Sci Ind Res. 2008;43(4):433-48.

Takatsuji M. Present status of completely-controlled plant factories. Shokubutsu Kankyo Kogaku. 2010;22(1):2-7.

Um YC, Oh SS, Lee JG, Kim SY, Jang YA. The development of container-type plant factory and growth of leafy vegetables as affected by different light sources. J Bio-Env. 2010;19(4):333-42.

Watanabe H. Light emitting diodes as the irradiation source for plant factories. Rev Laser Eng. 1997;25(12):836-40.

Zhou TY, Lou LL, Yang G, Al-Shehbaz IA. Brassicaceae (Cruciferae). In: Wu ZY, Raven PH, editors. Flora of China. BRASSICACEAE through SAXIFRAGACEAE, vol. 8. St. Louis: Science Press, Beijing and Missouri Botanical Garden Press; 2001.

\section{Publisher's Note}

Springer Nature remains neutral with regard to jurisdictional claims in published maps and institutional affiliations.

Ready to submit your research? Choose BMC and benefit from:

- fast, convenient online submission

- thorough peer review by experienced researchers in your field

- rapid publication on acceptance

- support for research data, including large and complex data types

- gold Open Access which fosters wider collaboration and increased citations

- maximum visibility for your research: over $100 \mathrm{M}$ website views per year

At $\mathrm{BMC}$, research is always in progress.

Learn more biomedcentral.com/submissions 